\title{
Existing forms and transformation of S-functional groups of sewage sludge of different seasons by using XPS method
}

\author{
Peiyi Zhong ${ }^{1,2, a}$, Jianhang Huang ${ }^{1,2, b}$, Haiwen $\mathrm{Wu}^{1,2, \mathrm{c}}$ and Wenhao Zeng ${ }^{1,2, \mathrm{~d}}$ \\ ${ }^{1}$ South China Institute of Environmental Sciences, Ministry of Environmental Protection, Guangzhou \\ 510655, PR China \\ ${ }^{2}$ Guangzhou Huake Environmental Engineering CO., Ltd, Guangzhou 510655, PR China
}

azhongpeiyi@scies.org, bhuangjianhang@scies.org, c1092811974@qq.com, d674097794@qq.com

Keywords: S-containing groups; existing form; XPS method; sewage sludge

Abstract. In this study, X-ray photoelectron (XPS) was used to investigate the sulfur existing forms and transformation of dewatered sewage sludge which collected form a wastewater treatment plant using $\mathrm{A}^{2} / \mathrm{O}$ process in different seasons. The S2p spectra obtained curves were resolved into 6 peaks: sulfate-S(170.0 $\pm 1.0 \mathrm{eV}), \quad$ sulfone-S(168.0 $\pm 0.5 \quad \mathrm{eV}), \quad$ sulfoxide/sulfite- $\mathrm{S}(166.0 \pm 0.5 \mathrm{eV})$, thiophene-S(164.1 $\pm 0.2 \mathrm{eV})$, sulfide-S $(163.3 \pm 0.4 \mathrm{eV})$ and mercaptan-S(162.2 $\pm 0.3 \mathrm{eV})$. The results show that the existing forms of sulfur can mainly be divided as inorganic-S and organic-S, the content of sulfur in the sewage sludge sample increased with the environmental temperature rising. The content of each component was closely related to the environmental temperature, inorganic sulfur decreased with the increasing environmental temperature, while organic sulfur increased with the raise of environmental temperature and reached the maximum value in July.

\section{Introduction}

Sewage sludge is unavoidable residual matter form waste water, and finding an environmental-friendly disposal of sewage sludge has become a severe challenge today[1]. As traditional methods of sewage sludge disposal including ocean dumping, landfill, agricultural application and building use are difficult to meet the economic and environmental requirement, thermal disposal of sewage sludge for energy utilization is regarded as a feasible disposal route with potential financial benefits[2-4]. Thermal treatment of sewage sludge is an excellent and proven disposal ways, which can depredate highly toxic persistent organic compounds and reduce sewage sludge volume excellently[5,6]. However, high content of sulfur $(0.2-1.6 \mathrm{wt} . \%)$ of sewage sludge supports the release of $\mathrm{SO}_{2}$ and $\mathrm{S}$-containing gaseous pollutants from combustion[7], which contributes to the air pollution such as acid rain[8].

Therefore, thermal conversion of sewage sludge is not widely used, despite many significant advantages it has. The generation of sulfur compounds during sludge pyrolysis/combustion mainly depends on the forms and proportions of sulfur of the sludge. As a mature and convenient method, X-ray photoelectron(XPS) was widely used in analysis the elemental content of solid samples[9.10]. A lot of studies have been done on the distribution and transformation of sulfur in coal[11-13], while there are few studies on the existing form and transformation of sulfur in sewage sludge.

In this study, dewatered sewage sludge samples were collected from a Guangzhou sewage treatment plant in January, April, July and October respectively, the existing forms and transformation of sulfur in different season sewage sludge samples were investigated.

\section{Materials and Methods}

Preparation and Property of Raw Sludge Sample. Sewage sludge sample used in this study was dewatered sludge which came from a municipal sewage treatment plant in Guangzhou, China. After natural drying in open area for 3-5 days, the sludge was milled below $75 \mu \mathrm{m}$, and then put into constant temperature and constant humidity box (T: $\left.20{ }^{\circ} \mathrm{C}, \mathrm{H}: 60 \%\right)$ before use. The proximate contents of samples were determined according to Chinese National Standard-Industrial analysis 
method of coal(GB/T 212-2008), and the elemental contents was detected by using an elemental analyzer (EA2000, EuroVector, Italy), the results are shown in Table 1.

Table 1. Proximate, ultimate analysis and chemical compositions of sludge samples.

\begin{tabular}{|c|c|c|c|c|c|c|c|c|c|c|}
\hline \multirow{2}{*}{ Sample } & \multicolumn{5}{|c|}{ Proximate analysis (wt.\%) } & \multicolumn{5}{|c|}{ Ultimate analysis (wt.\%, dry base) } \\
\hline & $\omega\left(\mathrm{M}_{\mathrm{t}}\right)$ & $\omega\left(\mathrm{M}_{\mathrm{ad}}\right)$ & $\omega\left(\mathrm{A}_{\mathrm{ad}}\right)$ & $\omega\left(\mathrm{V}_{\mathrm{ad}}\right)$ & $\omega\left(\mathrm{FC}_{\mathrm{ad}}\right)$ & $\omega(\mathrm{C})$ & $\omega(\mathrm{H})$ & $\omega(\mathrm{N})$ & $\omega(\mathrm{S})$ & $\omega(\mathrm{O})$ \\
\hline DTS-1 & 77.53 & 5.70 & 66.75 & 26.35 & 1.20 & 28.11 & 5.31 & 3.67 & 0.88 & 19.45 \\
\hline DTS-4 & 76.56 & 3.56 & 65.34 & 29.34 & 1.76 & 27.56 & 5.76 & 4.88 & 1.12 & 20.01 \\
\hline DTS-7 & 77.33 & 5.88 & 40.58 & 44.93 & 8.61 & 26.89 & 6.02 & 5.78 & 1.32 & 21.45 \\
\hline DTS-10 & 76.34 & 3.81 & 68.51 & 24.54 & 3.14 & 27.33 & 5.24 & 4.12 & 0.98 & 19.32 \\
\hline
\end{tabular}

Experimental Devices and Data Processing Methods. The content of sulfur in samples were analyzed by a XPS (Escalab 250Xi, Thermo, America), with $\mathrm{C} 1 \mathrm{~s}(284.6 \mathrm{eV})$ peak as the internal calibration, and the binding energy $(\mathrm{eV})$ as the abscissa, relatively intensity $(/ \mathrm{s})$ as the vertical of XPS spectra. Based on the difference of the binding energies of different existing forms of sulfur, the XPS spectra of S2p were obtained by using XPS peak 4.1 software (50\%Lorentzian-Gaussian) for peak fitting and type Shirley was used to deduct the background value. The S2p spectra obtained curves

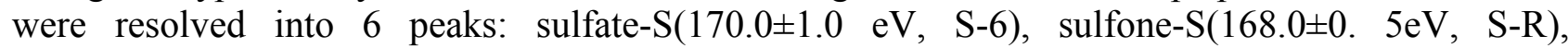
sulfoxide/sulfite-S(166.0 $\pm 0.5 \mathrm{eV}, \mathrm{S}-4)$, thiophene-S(164.1 $\pm 0.2 \mathrm{eV}, \mathrm{S}-\mathrm{C})$, sulfide $(163.3 \pm 0.4 \mathrm{eV}, \mathrm{S}-2)$ and mercaptan- $\mathrm{S}(162.2 \pm 0.3 \mathrm{eV}, \mathrm{S}-\mathrm{H})$, each binding energy was selected according reference literatures[14-16].

In order to analyzer the proportion of different forms of sulfur in the sewage sludge sample, the relative amount of each component was calculated by the area of fitting peak. The ratio of different form of sulfur in total sulfur and sewage sludge sample were calculated as equation (1) and (2) respectively.

$\% \mathrm{~S}(\%)=$ area of fitting peak/total area of fitting peaks $\times 100 \%$

$\% \mathrm{~T}(\%)=\% \mathrm{~N} \times$ the content of sulfur in sewage sludge sample $/ 100(\%)$

\section{Results and Discussions}

The concentration of sulfur in the sewage sludge by using XPS were shown in Table 2. Comparing with the results in Table 1, it can be found the proportions of sulfur by using elemental analyzer were higher than the that of XPS method. The reasons can be explained as that: first, as hydrogen can't be detected by XPS, the content of it was not included, while the content of hydrogen in sludge sample was relatively high (3\%-5\%). Second, XPS can only analysis the surface elemental content, then the consistency of elements on the surface and inside has a certain influence on the quantification. Despite the differences of sulfur content using elemental analyzer and XPS, the variation pattern was similar along with different seasons and the sulfur contents detected by two methods were close. To some extent, it verified that XPS method is feasible for studying the forms of sludge in sewage sludge sample.

Table 2. Sulfur content in sludge sample by XPS.

\begin{tabular}{|c|c|c|c|c|}
\hline & DTS-1 & DTS-4 & DTS-7 & DTS-10 \\
\hline S2p (\%) & 0.34 & 0.48 & 0.57 & 0.45 \\
\hline
\end{tabular}

The decomposition diagrams of S2p peak of sewage sludge sample of different seasons were shown in Figure 1. As can be seen in Figure 1, the S-containing functional groups in sludge can be resolved into 6 peaks: sulfate-S, sulfone-S, thiophene-S, sulfide-S, sulfoxide/sulfite-S and mercaptan-S. The area of fitting peaks were integrated, and the ratio of different S-containing functional groups of total sulfur and sludge were calculated. The results are shown in Figure 2. 

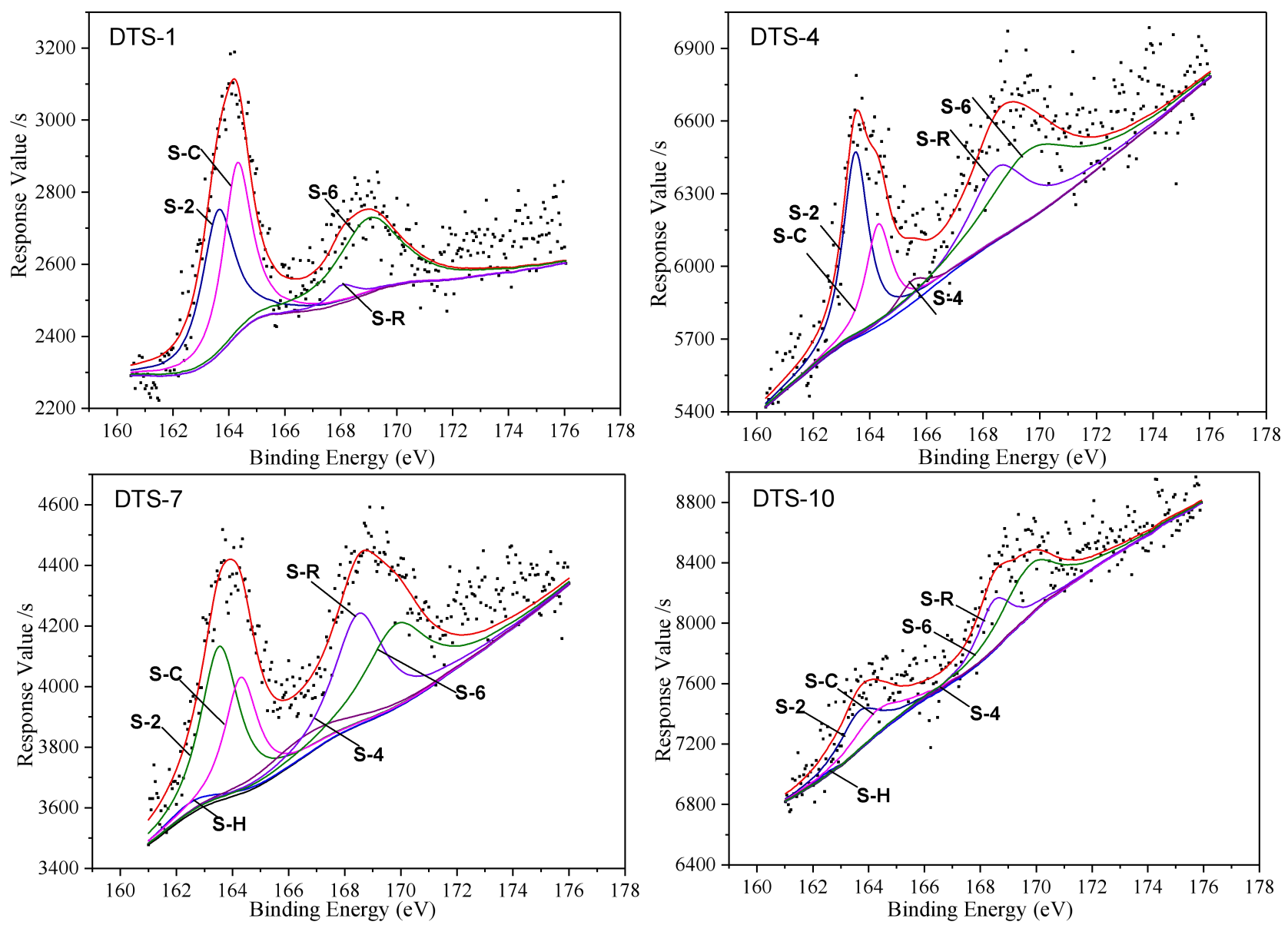

Figure 1. Decomposition diagram of S2p peak of sewage sludge sample.

As can be seen in Figure 2, the contents of sulfur in four samples were DTS-7 $>$ DTS-4 $>$ DTS-10 $>$ DTS-1, and the content of sulfur in the sewage sludge sample increased with the environmental temperature rising. Comparing the existing forms of sulfur in the four examples with different sampling time, it can be found that sulphate-S didn't change much with the seanonal variation, which accounted for $0.15 \%$ of total sludge. The ratio of sulfone-S in sample DTS- 1 was much smaller than the other three samples. Sulfoxide/sulfite-S was not detected in sample DTS-1. The variation trend of triophen-S and sulfide-S was consistent with that of total $S$ trend, and the contents of mercaptan-S in four samples were low.

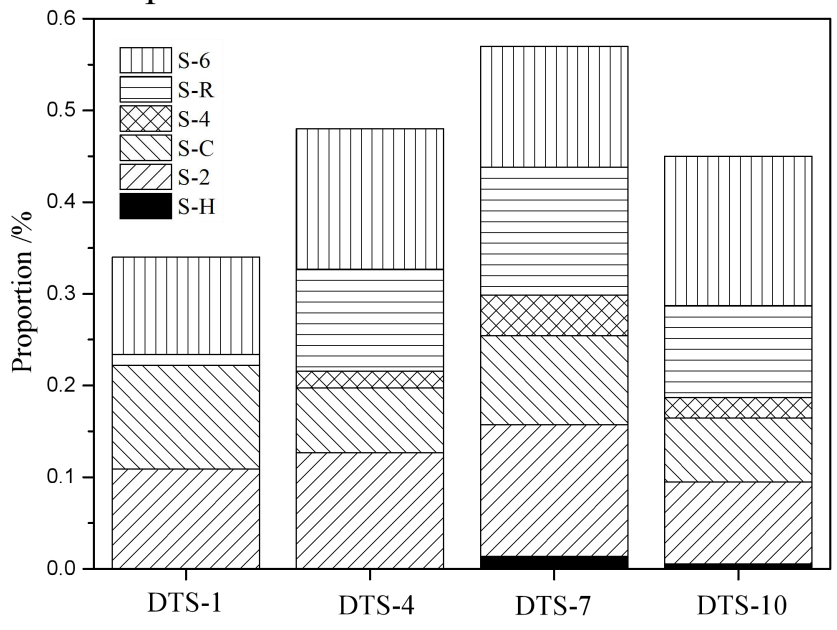

(1)\% $\mathrm{T}$

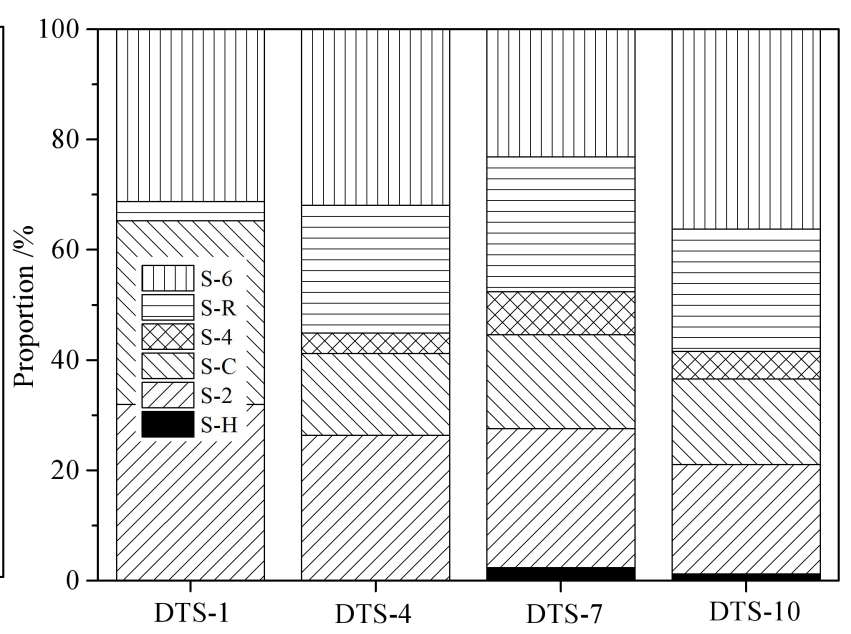

(2)\%S

Figure 2. The proportion of different S-containing function groups

Sulfur in the sewage sample can be divided into inorganic-S (sulfate-S, /sulfite-S, sulfide-S and) and organic-S (sulfone-S, sulfoxide-S, thiophene-S and mercaptan-S). Sulfate-S, sulfone-S, 
thiophene-S and sulfide-S took a large proportion of total sulfur, while the ratio of thiophene-S and sulfoxide/sulfite-S were smaller. The proportion of inorganic sulfur decreased at first, and then raise from $63.24 \%$ in January to $48.38 \%$ in July, and increased to $56.06 \%$ in October, which showed that the content of inorganic sulfur in sludge decreased with the increase of environmental temperature. As for organic sulfur, the main components were sulfone-S and thiophene-S, the ratios of mercaptan-S in four samples were less than 3\% of total sulfur, thiophene-s was less than $10 \%$, and both mercaptan-S and thiophen-S achieved the maximum in July, which were $2.34 \%$ and $17.03 \%$ respectively. Except for DTS-1, the content of sulfone-S in other three samples reached $20 \%$ of total sulfur content, while for thiophene-S, the trend with sampling time was opposite, in which the highest proportion of it was $33.27 \%$ in January. Contrary to the seasonal distribution of inorganic sulfur, organic sulfur increased with the raise of environmental temperature and reached the maximum value in July.

\section{Conclusions}

1. In this study, X-ray photoelectron(XPS) was used to investigate the existing form and transformation of sulfur in seasonal collected sewage sludge sample, the S2p spectra obtained curve

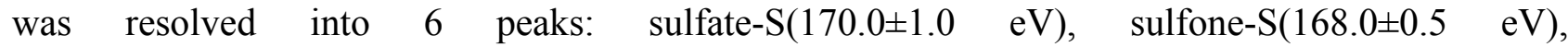
sulfoxide/sulfite-S(166.0 $\pm 0.5 \mathrm{eV}), \quad$ thiophene-S $(164.1 \pm 0.2 \mathrm{eV}), \quad$ sulfide $(163.3 \pm 0.4 \mathrm{eV})$ and mercaptan-S(162.2 $\pm 0.3 \mathrm{eV})$.

2. The content of sulfur in fore samples is DTS-7 $>$ DTS-4 $>$ DTS-10 $>$ DTS-1, and the content of sulfur in the sewage sludge sample increased with the environmental temperature rising.

3. The existing forms of sulfur can mainly be divided into inorganic-S and organic-S, and the former was dominant. The inorganic-S was mainly in the form of sulfate and sulfide, and the organic-S was mainly in the form of sulfone, thiophene. Sulfate-S, sulfone-S, thiophene-S and sulfide-S take a large proportion of total sulfur, while the ratio of thiophene-S and sulfoxide/sulfite-S were smaller.

4. The content of each component was closely related to the environmental temperature: inorganic sulfur compound reached its peak value in January, which decreased with the increase of environmental temperature; while organic sulfur increased with the raise of environmental temperature and reached the maximum value in July.

\section{Acknowledgements}

This work was financially supported by the National Natural Science Foundation of China (51778264), Project of Science and Technology Program of Guangdong Province(2017B020237002), Program for the Young Top-notch Talents of Guangdong province (2016TQ03Z576), and Pearl River S\&T Nova Program of Guangzhou (201610010150).

\section{References}

[1] Y. Wang, G. Chen, Y. Li, B. Yan and D. Pan: Waste Manage. Vol. 33(2013), p. 2408

[2] P. Manara and A. Zabaniotou. T: Sust. Energ. Rev. Vol. 16 (2012), p. 2566

[3] V.K. Tyagi and S.L. Lo: Sust. Energ. Rev. Vol. 25 (2013): p. 708

[4] I.Font, G. Gea, M. Azuara, J Ábrego and J. Arauzo: Sust. Energ. Rev. Vol. 16 (2012): p. 2781

[5] R. Barbose, N. Lapa, D. Boavida, H. Lopes, I. Gulyurtlu and B. Mendes: J. Hazard. Mater. Vol. 170(2009), p. 902

[6] N. Skoglund, L. Bäfver, J. Fahlström, E. Holmén and C. Renström: Fuel Process. Vol. 141(2016), p. 196

[7] Information on: http://www.doc88.com/p-6631255944179.html 
[8] M. Aznar, M.S. Anselmo, J.J. Manyà and M.B. Murillo: Energy Fuels Vol. 23(2009), p. 3236

[9] M.A. Wojtowicz, J.R. Pels and J.A. Moulijn: Fuel Vol 74(1995), p. 507

[10] M.L. Gorbaty and S.R. Kelemen: Fuel Process. Technol. Vol. 71(2001), p. 71

[11] Y.H. Liu, D. F. Che and T.M. Xu: Journal of Xi' an Jiaotong University, Vol. 38(2004), p. 101(in Chinese)

[12]M.L. Gorbaty and S.B. Kelemen: Fuel Process. Technol. Vol 71(2001), p. 71

[13] M. Li, J.H. Yang, Q.F. Zhang, H.Z. Chang and H. Sun: Journal of Fuel Chemical and Technology Vol 41(2013), p. 1287(in Chinese)

[14] Y. Dote, T. Hayashi, A. Suzuki A and T. Ogi: Fuel Vol. 71(1992), p. 1071

[15] A. Dominguez, J.A. Menendez, M. Inguanzo, P.L. Bernad and J.J. Pis: J. Chromatogr. A Vol. (1012)2003, p. 193

[16] P. Faure, F. Vilmin, R. Michels and E. Jarde: J. Anal. Appl. Pyrol. Vol. 62(2002), p. 297 